\title{
Compliance of adolescents with coeliac disease with a gluten free diet
}

\author{
M Mayer, L Greco, R Troncone, S Auricchio, M N Marsh
}

\begin{abstract}
A cohort of 123 patients with coeliac disease, diagnosed in the first three years of life and followed up for at least 10 years, was reevaluated during the teenage period in terms of compliance with the diet and clinical state. Mucosal structure and lymphocytes were assessed in small intestinal biopsy specimens obtained from 36 subjects, by computerised image analysis. Of these adolescents with coeliac disease, $65 \%$ were adhering to a strict gluten free diet, $11.4 \%$ were on a gluten free diet but with occasional gluten intake, and $23.6 \%$ were on a gluten containing diet. Clinical symptoms occurred more frequently in patients on a gluten containing diet, but not in patients on a semistrict diet. Occasional intake of small amounts $(0.06-2 \mathrm{~g} / \mathrm{day})$ of gluten did not produce increased concentrations of antigliadin antibodies but resulted in an appreciably increased crypt epithelial volume and expanded crypt intraepithelial lymphocyte population.
\end{abstract}

A life long gluten free diet is recommended to avoid the longterm risks associated with coeliac disease. ${ }^{1-6}$ Dietary compliance in relation to clinical, biochemical, and histological outcome has been the object of a few follow up studies in the past $^{7-10}$ and more recently. ${ }^{11-13}$ These studies generally showed poor dietary compliance in teenagers with coeliac disease, with only about $50 \%$ adhering to a gluten free diet. It is likely that the rate of compliance is even lower, as many of those declaring that they kept to a strict gluten free diet had appreciable mucosal abnormalities. ${ }^{1213}$

The conclusion that a strict gluten free diet should be maintained for life, strongly recommended by all investigators, has been more recently challenged both because a substantial proportion of patients seem unable to maintain it and because the intake of small amounts of gluten has been reported not to produce appreciable clinical, laboratory, or histological consequences. ${ }^{112} 1{ }^{14}$ In fact, short periods of 2.5-5 g of gluten daily did not cause clear cut histological changes of the small intestinal mucosa in a cohort of adult patients with coeliac disease. ${ }^{\text {is }}$
In this study patients diagnosed at least 10 years previously and who were now adolescents were evaluated (i) to assess their compliance with a gluten free diet and (ii) to relate compliance to general state of health, to serum antigliadin antibody concentrations, and to the morphometric features of small intestinal mucosa.

\section{Patients and methods}

A total of 123 adolescents ( 52 males, 71 females), mean age $13 \cdot 7$ years, range $10 \cdot 6-23)$, diagnosed in our department in the first three years of life, were reinvestigated after approximately 10 years (mean 11.5 years, range 9-16). Each was seen at least annually for review, and those on strict and semistrict diets had mean (SD) annual attendance rates of $15 \cdot 59(5 \cdot 7)$ and $15 \cdot 09(5 \cdot 3)$, respectively. The non-compliant group had 12.51 (5.1) attendances per year, differing significantly $(t=2.56 ; p=0.012)$ from those on strict dietary control.

Cases were allocated to one of the following categories: (1) (a) Diagnosis by European Society of Pediatric Gastroenterology and Nutrition (ESPGAN) criteria (three biopsies): 67 cases (54.5\%). (b) Flat mucosa on a gluten containing diet, clinical remission on a gluten free diet, and clinical and biochemical relapse (impaired xylose excretion or a rise in antigliadin antibody titre, or both) after gluten challenge: 33 cases $(26 \cdot 8 \%)$. (2) Flat mucosa in the acute phase, clinical remission on a gluten free diet but not challenged by any standardised procedure: 23 cases $(18 \cdot 7 \%)$.

\section{DIETARY ASSESSMENT}

An accurate dietary assessment of the amounts of gluten ingested per day in the past week and month was carried out by trained personnel, using a precoded questionnaire. Only one dietary assessment per patient was undertaken by our dietitian, who also filled in the form. Particular care was given to seeking out indiscretions - for example, with social events where dietary control was most likely to be relaxed. In general, the dietitian's assessment agreed closely with that of the physician's, which was gained through routine reviews of patients in the clinic.

\section{CLINICAL AND LABORATORY DATA}

Clinical evaluation included inspection of the skin, hair, muscle mass, genitalia, and pubertal state, and the presence of aphthous ulcers, dermatitis herpetiformis bullae, and tooth enamel development. The latter changes were graded with respect to colouring of enamel, followed by evidence of increasing structural defects (grades 1-3). the diagnostic protocol

\begin{tabular}{lllll}
\hline & \multirow{2}{*}{$\begin{array}{l}\text { Total No of } \\
\text { patients }\end{array}$} & \multicolumn{4}{l}{ Daily gluten content } \\
\cline { 3 - 5 } \cline { 4 - 5 } Diagnosis by & None & $0 \cdot 06-2$ g/day & $>2$ g/day \\
\hline No(\%) on ESPGAN protocol & 67 & $51(76 \cdot 1)$ & $11(16 \cdot 4)$ & $5(7 \cdot 5)$ \\
No(\%) not on ESPGAN protocol & 56 & $29(51 \cdot 7)$ & $3(5 \cdot 3)$ & $24(43)$ \\
\hline
\end{tabular}

$\chi^{2}=20 \cdot 49 ; p<0.001$ 
The height and weight of the patients, and of both parents, were obtained by quality controlled instruments and procedures, according to Cameron. ${ }^{16}$ Standard deviation scores were obtained by comparison with a healthy normal population drawn from the same geographic region. ${ }^{17}$ Continuous correction for parents' stature, adjusted for sex, was performed by a covariate model (ANOVA). Last month point prevalence of clinical symptoms was obtained by an inquirer 'blind' to the subject's diet.

Specific IgG and IgA gliadin antibodies were measured by enzyme linked immunosorbent assay ${ }^{18}$ and the results expressed as a percentage of a positive reference serum. The upper control reference range was taken as $25 \%$ and $23 \%$, for $\mathrm{IgG}$ and $\mathrm{IgA}$ isotypes, respectively.

\section{MORPHOMETRIC ANALYSIS}

Patients were offered a jejunal biopsy and this was accepted by 36 (19 males and 17 females, median age 14 years, range 11-19 years).

Jejunal biopsy specimens were obtained with a Watson capsule from the duodenal-jejunal flexure, fixed in $10 \%$ formalin, embedded in paraffin wax, sectioned at $5 \mu \mathrm{m}$ thickness and stained with haematoxylin and eosin. Ten consecutive $5 \mu \mathrm{m}$ sections were mounted per slide, and alternate sections were analysed to ensure that no cell was counted twice. The sections were projected through a high resolution colour television camera to a MOP-Videoplan (KontronReichert, Slough, England) computerised image analysis system.

To calculate surface and crypt epithelial volumes, the appropriate sectioned profiles were outlined with the scribing cursor, together with the length of underlying muscularis mucosae. Irrespective of the degree of mucosal abnormality, the compartmental volumes are calculable and comparative since all measurements were standardised to a constant test area of muscularis mucosae $\left(100 \times 100=10^{4} \mu \mathrm{m}^{2}\right)$. Mucosal compartment volumes comprised surface epithelial volume $\left(\mathrm{V}_{\mathrm{SE}}\right)$, and crypt epithelial volume $\left(\mathrm{V}_{\mathrm{Cr}}\right)$, and these values were expressed in terms of their equivalent cube volumes $\left(\times 10^{6}\right.$ $\left.\mu \mathrm{m}^{3}\right)$. Coefficients of variation for successive measurements per specimen were $<10 \%$ : these calculations are automatically included in the print out by the manufacturer's software programme.

To measure the intraepithelial lymphocyte population within a defined tissue volume, the mean nuclear diameter (Dn) corrected for 'lost

TABLE II Symptoms experienced by adolescents in relation to their compliance with a gluten free diet

\begin{tabular}{llll}
\hline & \multicolumn{3}{l}{ Daily gluten content } \\
\cline { 2 - 4 } & $\begin{array}{l}\text { None } \\
(n=80)\end{array}$ & $\begin{array}{l}0 \cdot 06-2 \mathrm{~g} \\
(n=14)\end{array}$ & $\begin{array}{l}>2 g \\
(n=29)\end{array}$ \\
\hline Total No (\%) with symptoms & $27(33 \cdot 7)$ & $4(28 \cdot 6)$ & $19(65 \cdot 5)$ \\
Recurrent abdominal pain & 15 & 2 & 9 \\
Migraine & 9 & 1 & 7 \\
$\begin{array}{l}\text { Diarrhoea } \\
\text { Constipation (evacuation }\end{array}$ & 3 & 1 & 2 \\
$\begin{array}{l}\geq 3 \text { days } \\
\text { No(\%) with no symptoms }\end{array}$ & $-53(66 \cdot 3)$ & $10(71 \cdot 4)$ & $10(34 \cdot 5)$ \\
\hline
\end{tabular}

$\chi^{2}=9 \cdot 85 ; p=0.0072$
TABLE III Clinical findings and associated diseases in adolescents in relation to their compliance with a gluten free diet

\begin{tabular}{llll}
\hline & \multicolumn{3}{l}{ Daily gluten content } \\
\cline { 2 - 4 } & $\begin{array}{l}\text { None } \\
(n=80)\end{array}$ & $\begin{array}{l}0.06-2 \mathrm{~g} \\
(n=14)\end{array}$ & $\begin{array}{l}>2 \mathrm{~g} \\
(n=29)\end{array}$ \\
\hline Clinical findings: & 5 & - & 1 \\
$\begin{array}{l}\text { Eczema } \\
\text { Enamel hypoplasia }\end{array}$ & 4 & 1 & 2 \\
Gingival aphthae & 1 & - & - \\
Pubertal delay & - & - & 1 \\
$\begin{array}{l}\text { Associated diseases: } \\
\text { Psoriasis }\end{array}$ & 2 & - & - \\
Thyroiditis & 2 & - & - \\
Behavioural disturbances & 1 & - & - \\
Epilepsy & 2 & - & - \\
Hearing deficit & 4 & - & - \\
\hline
\end{tabular}

profiles'19-20 and for 'non-sagittal' sectioning $^{21}$ was calculated to determine 'effective section thickness.' The latter is obtained from the relation $\mathrm{t}+\mathrm{Dn}$, where $\mathrm{t}$ is the actual section thickness $(5 \mu \mathrm{m}) .{ }^{21}$ The absolute number of intraepithelial lymphocytes within either a surface $\left(\mathrm{N}_{\mathrm{V}, \mathrm{SE}}\right)$, or crypt $\left(\mathrm{N}_{\mathrm{V}, \mathrm{Cr}}\right)$, epithelial volume relative to a $10^{4}$ $\mu \mathrm{m}^{2}$ 'test area' of muscularis mucosae, is obtained by counting the epithelial lymphocyte profiles within surface or crypt epithelium overlying a length of muscularis mucosae equivalent to $10000 \mu \mathrm{m}$ and dividing this value by $(\mathrm{t}+\mathrm{Dn})$.

\section{STATISTICS}

Group means were compared with unpaired $t$ test or Fisher's test; a p value $<0.05$ was considered to be significant.

\section{Results}

COMPLIANCE WITH GLUTEN FREE DIET

Eighty $(65 \%)$ patients were found to be on a gluten free diet, $29(23.6 \%)$ were on a normal gluten containing diet (average daily gluten content $\approx 15 \mathrm{~g}$ ), while $14(11 \cdot 4 \%)$ were on a gluten free diet with occasional intake of small amounts of gluten ranging from $0.06-2 \mathrm{~g} /$ day (average $0.73 \mathrm{~g} /$ day). Of these, nine ingested $<1$ g/day and five approximately 1-2 g/day. Bread and cakes were the most frequent source of gluten. The non-compliers on a 'gluten free diet' were all fully aware of their irregular diet: those consuming small amounts of gluten occasionally abandoned the diet completely to avoid difficulties during their social life.

To analyse factors affecting dietary compliance, when school levels standardised for age were compared, no differences were found between the three groups of patients. When compliance with the diet was analysed in relation to the diagnostic protocol adopted (Table I), patients who had been diagnosed on the basis of the ESPGAN criteria seemed to cope better with a gluten free diet $\left(\chi^{2}=20 \cdot 4, p<0 \cdot 001\right)$. It should be noted that of 23 cases never challenged by standardised procedures, 18 were taking a normal gluten containing diet. They had spontaneously reintroduced the gluten in the diet from an average age of 6.6 years (range 1-12 years). Only five patients diagnosed according to ESPGAN criteria were on a gluten containing $\operatorname{diet}$ (Table I). 
TABLE IV Height and weight in adolescents in relation to their compliance with the gluten free diet

\begin{tabular}{llll}
\hline & \multicolumn{3}{l}{ Daily gluten content } \\
\cline { 2 - 4 } & $\begin{array}{l}\text { None } \\
(n=80)\end{array}$ & $\begin{array}{l}0.06-2 g \\
(n=10)\end{array}$ & $\begin{array}{l}>2 g \\
(n=28)\end{array}$ \\
\hline Standardised height (mean) & -0.63 & -0.72 & -0.11 \\
Standardised weight (mean) $\dagger$ & +0.28 & -0.42 & -0.04 \\
\hline
\end{tabular}

Standardised height and weight have been obtained by subtracting from the expected normal values for age and sex and dividing to obtain the age specific standard deviation.

*Analysis of variance $\mathrm{F}$ test $=0 \cdot 9$, not significant.

†Analysis of variance $F$ test $=0 \cdot 7$, not significant.

\section{CLINICAL AND LABORATORY DATA}

Last month point prevalence of clinical symptoms in respect of the diet is shown in Table II. Patients on a normal diet described more symptoms than either patients on a gluten free or those on a semistrict gluten free diet $\left(\chi^{2}=9.85\right.$, $\mathrm{p}=0.007):>50 \%$ of patients on the gluten containing diet reported appreciable complaints, such as recurrent abdominal pain and migraine. No differences were evident between patients on a strict and a semistrict gluten free diet.

Clinical examination showed abnormal features in 15 cases (12\%): enamel hypoplasia and eczema were particularly evident. As Table III shows, no differences were found between groups. Associated diseases were all recorded in the gluten free group.

The standardised heights (corrected for parents heights) and weights for the whole group of patients did not differ greatly from those of the normal healthy peer population. No differences in height and weight were recorded in relation to dietary compliance, although the weight of patients on a gluten free diet was highest (Table IV).

Raised IgG or IgA antigliadin antibody concentrations, or both, were observed in $18.7 \%$, $27 \cdot 5 \%$, and $14 \cdot 2 \%$ of the patients on a gluten free diet, on a gluten containing diet, and on a semistrict gluten free diet, respectively (Table V).

MORPHOMETRY ANALYSIS (TABLE VI, FIGS 1-3) Small intestinal biopsies were performed on 36 patients. Three specimens were excluded from evaluation because of poor preservation, thus leaving mucosae from (i) six patients on strict gluten restriction, (ii) 14 on a semistrict diet (0.6-2 g gluten daily), and (iii) 13 on a gluten containing diet ( $\gg 2$ g daily).

Morphometric analysis of the mucosae (Fig 1)

TABLE V Serum antigliadin antibody concentrations in adolescents in relation to their compliance with a gluten free diet

\begin{tabular}{lcll}
\hline \multicolumn{4}{c}{ Daily gluten content } \\
\cline { 2 - 4 } $\begin{array}{l}\text { Antigliadin } \\
\text { antibody }\end{array}$ & $\begin{array}{l}\text { None } \\
(n=80)\end{array}$ & $\begin{array}{l}0 \cdot 06-2 g \\
(n=14)\end{array}$ & $\begin{array}{l}>2 g \\
(n=29)\end{array}$ \\
\hline $\begin{array}{l}\text { IgG }>25 \% \star \\
\text { IgA }>23 \%,\end{array}$ & $\begin{array}{l}9(11 \cdot 2 \%) \\
\text { IgG }>25 \% \text { or IgA }>23 \%, \\
\text { or both }\end{array}$ & $\begin{array}{l}9(11 \cdot 2 \%) \\
2(14 \cdot 2 \%)\end{array}$ & $\begin{array}{l}7(24 \cdot 1 \%) \\
6(20 \cdot 6 \%)\end{array}$ \\
\hline
\end{tabular}

None of the differences were significant.

Note: upper control reference ranges were $25 \%$ for IgG and $23 \%$ for IgA isotypes. in the 14 cases on a semistrict gluten free diet, compared with those on a strict diet, showed three with normal villi, four with a flat mucosa, and the remaining seven with considerable villous shortening. In nine of these mucosae, however, there was pronounced crypt hypertrophy and infiltration of crypt epithelium by an increased population of intraepithelial lymphocytes (Fig 2). Among these patients were four with a clearly damaged mucosa (Fig 1 ).

When compared with patients on a strict gluten free diet all but one of the 13 patients on a gluten containing diet ( $>2$ g gluten daily) showed significant decreases in surface epithelial volume and increases in crypt epithelial volume (Fig 1). The absolute number of intraepithelial lymphocytes in surface epithelium was not significantly decreased (Fig 2), while in crypts it was significantly increased compared with the gluten free diet group (Fig 3).

\section{Discussion}

Low compliance with a gluten free diet in adolescent coeliac patients has often been reported. ${ }^{2789-1322}$ The data show that $65 \%$ of our patients maintained a strict gluten free diet; $11 \cdot 4 \%$ occasionally consumed small amounts of gluten $(<2 \mathrm{~g} /$ day $)$, while the percentage of patients on a gluten containing diet $(23.6 \%)$ was much lower compared with the roughly $40 \%$ reported by others. ${ }^{7-9}$

We did not thoroughly analyse the social factors that could influence attitudes to diet, but in our cohort school level, sex, and age did not seem to affect compliance. It is reasonable to believe, as has been shown in other studies, ${ }^{13}$ that low social class or poor family education may negatively influence dietary compliance, as in any other chronic disease. Nevertheless, we do not think that the cost of gluten free food plays a major part: this was taken into account in a recent study ${ }^{24}$ but did not apparently create difficulties for adult patients with coeliac disease. Moreover, in Italy any coeliac patient regardless of age receives gluten free products free for life under the national health system. The Italian Coeliac Society also plays an active part for its membership by working to improve knowledge of the management of the disease.

Patients diagnosed according to the complete ESPGAN protocol showed the best longterm compliance with a gluten free diet. It might be that the diagnostic criteria requiring a supervised gluten challenge would shorten the time of gluten reintroduction ${ }^{18}$ and possibly reinforce the consequent dietary counselling. But a selection bias might also be present, such that those patients who accept the ESPGAN protocol are probably more likely to adhere to a strict diet. Since the ESPGAN protocol is undergoing revision ${ }^{25}$ because the diagnostic accuracy seems to be good before a gluten challenge, a controlled challenge individually planned for each patient should be considered with respect to longterm compliance.

Although clinical symptoms occurred more frequently in patients on a gluten containing diet, auxological parameters for the whole group were not noticeably lower than for normal 


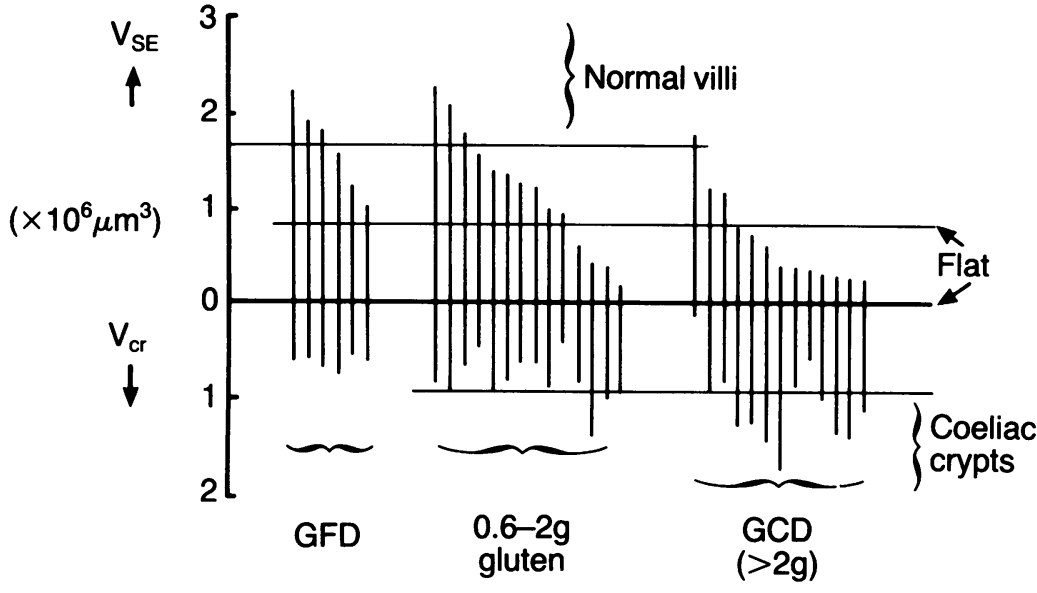

Figure 1: Volume compartments for surface epithelium $\left(V_{S E}\right)$ and crypt epithelium $\left(V_{C r}\right)$ are indicated on left hand axis for each of the three groups studied ( $G F D=$ strict gluten free group; 0.6-2 g gluten=moderate consumption group; $G C D=$ group consuming $>2$ g gluten daily) by jejunal biopsy specimens. Lower reference range $(1 \cdot 6)$ for control villi, and upper reference ranges for flat coeliac mucosa $(0 \cdot 95)$, and control crypts $(1 \cdot 0)$, are indicated by horizontal lines.

healthy peer controls, except that the group on a gluten free diet weighed more than the others. In previous studies non-compliers were more often asymptomatic despite having abnormal mucosa and laboratory data: when auxological parameters have been considered, all patients presented with weights and heights below the 50th percentile of standards. ${ }^{10-13}$ The findings of associated diseases in 12 cases, all in the gluten free group, may be explained by the improved clinical supervision, including that of diet.

Antigliadin antibody concentrations were not helpful in assessing the compliance of either group of patients. Moreover, for the group on a semistrict gluten free diet neither symptoms nor antigliadin antibody concentrations were found to be reliable markers of gluten ingestion, in agreement with previous studies. ${ }^{15}$

Standard histological evaluation of the small intestinal mucosa showed normal mucosae in eight biopsied patients on a gluten free diet, some degree of mucosal damage in four, and normal mucosa in 10 in the semistrict gluten free diet group, while all the subjects but one on a gluten containing diet had a flat, or severely damaged, small intestinal mucosa. The only patient with a normal mucosa on a gluten containing diet for eight years was a patient initially diagnosed in the past by strict ESPGAN criteria. Only a few similar cases have been reported $^{23}$ and a relapse ${ }^{26}$ documented after a very long period: clearly, more time and more

TABLE VI Morphometric analysis of jejunal biopsy specimens from adolescents in relation to their compliance with the gluten free diet

\begin{tabular}{|c|c|c|c|}
\hline & \multicolumn{3}{|l|}{ Daily gluten content } \\
\hline & None $(n=6)$ & $0.06-2 g(n=14)$ & $>2 g(n=13)$ \\
\hline \multirow{3}{*}{$\begin{array}{l}\text { Surface epithelial volume }\left(\times 10^{6} \mu \mathrm{m}^{3}\right) \\
(\text { mean }(\mathrm{SD})) \\
\text { Crypt epithelial volume }\left(\times 10^{6} \mu \mathrm{m}^{3}\right) \\
\text { (mean }(\mathrm{SD})) \\
\text { Surface intraepithelial lymphocytes } \\
\left.\text { (per } 10^{4} \mu \mathrm{m}^{2} \text { muscularis mucosae }\right) \\
(\text { log mean }(1 \mathrm{SD} \text { range) })\end{array}$} & $1.61(0.48)$ & $1 \cdot 16(0.63)$ & $0.63(0.46)^{\star}$ \\
\hline & $0.65(0.07)$ & $0.82(0.24)^{\star}$ & $1.12(0.42)^{\star}$ \\
\hline & $2.22(2.04-2.40)$ & $2.12(1.93-2.31) t$ & $112(0+42)$ \\
\hline \multirow{2}{*}{$\begin{array}{l}\text { Crypt intraepithelial lymphocytes } \\
\text { (per } 10^{+} \mu \mathrm{m}^{2} \text { muscularis mucosae) } \\
\text { (log mean (1SD range)) }\end{array}$} & & & $211+202521$ \\
\hline & $1.50(1.42-1.58)$ & $1.71(1.50-1.91) \dagger$ & $1 \cdot 80(1 \cdot 51-2 \cdot 1) \dagger$ \\
\hline
\end{tabular}

Compared with gluten free diet group: ${ }^{\star} \mathrm{p}<0.05 ; \mathrm{fp} \leq 0.02$
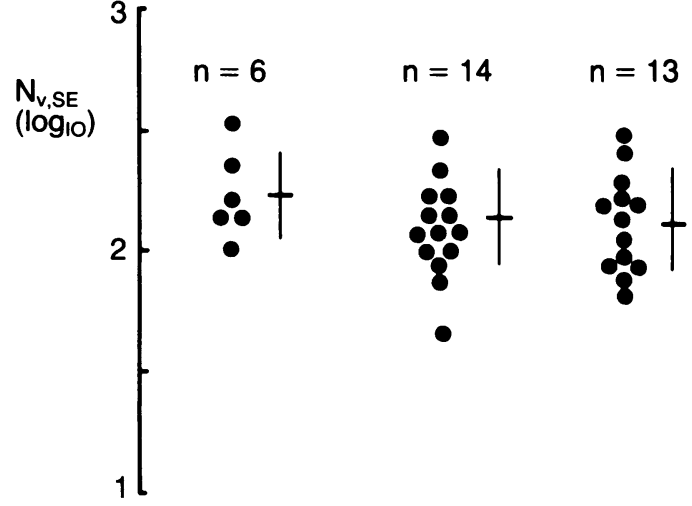

Figure 2: Total population size $\left(N_{\mathrm{V}, \mathrm{SE}}\right)$ for intraepithelial lymphocytes in surface epithelium is shown for gluten free group $(n=6)$, partial gluten free $(n=14)$, and free diet group $(n=13)$. There are no significant differences between groups.

cases are necessary to understand the final prognosis in terms of clinical and histological outcome in these patients.

By computerised morphometric analysis we were able to show an appreciable decrease in surface eithelial volume, and an appreciable increase in crypt epithelial volume passing from the gluten free diet group to the gluten containing patients. This trend, from normal to flat, has been shown in previous studies in treated coeliac patients when challenged with increasing amounts of peptic-trýptic digest of gluten." Surface intraepithelial lymphocytes were decreased in those on a gluten containing diet compared with the gluten free group, while crypt epithelium showed appreciable increases in intraepithelial lymphocytes.

The fall in the absolute number of intraepithelial lymphocytes in the surface epithelium of flat mucosae is a real phenomenon and does not conflict with the fact that their density is increased $^{27}$; it depends on what is being expressed as cell population sizes in terms of densities ${ }^{28}$ rather than absolute numbers. ${ }^{19-21}$

It is notable that only accurate morphometric analysis was able to discriminate about $50 \%$ patients ingesting very small amounts of gluten without accompanying clinical problems, a specific antibody response, or obvious alteration to normal mucosal architecture. The data of an expanded intraepithelial lymphocyte population suggests that small amounts of gluten are able to activate local intestinal immunity. The fact that

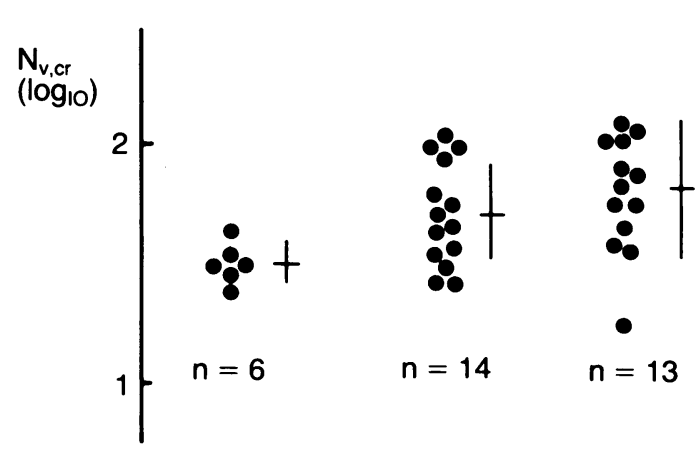

Figure 3: Total population size $\left(N_{\mathrm{V}, \mathrm{Cr}}\right)$ for intraepithelial lymphocytes in crypt epithelium for each of the three groups described in Figure 2. There were significant increases in described in Figure 2. There were significant increases in
intraepithelial lymphocytes in both the group on a partial gluten free diet and the group on a gluten containing diet. 
some tumours (jejunal lymphoma) reported in coeliac disease ${ }^{29}$ are likely to derive from an expanded intraepithelial T lymphocyte population and that a gluten free diet has a protective role against malignancy in coeliac disease ${ }^{6}$ is consistent with our observations indicating that a strict gluten free diet for life should always be recommended.

1 Harris OD, Cooke WT, Thompson $\mathrm{H}$, Waterhouse JAH Malignancy in adult celiac disease and idiopathic Malignancy in adult celiac disease
steatorrhea. $A m \mathcal{F}$ Med $1967 ; 42: 899-912$.

2 Holmes GKT, Stokes PL, Sorahan TM, Prior P, Waterhouse JAH, Cooke WT. Coeliac disease, gluten-free diet and malignancy. Gut 1976; 17: 612-9.

3 Cooper BT, Holmes GKT, Ferguson R, Cooke WT. Coeliac disease and malignancy. Medicine 1980; 59: 249-61.

4 Cooke WT, Holmes GKT. Coeliac disease. London: Churchill Livingstone, 1984.

5 Walker-Smith J. Diseases of the small intestine in childhood. 3rd ed. Sevenoaks: Butterworths, 1988.

6 Holmes GKT, Prior P, Lane MR, Pope D, Allan RN. Malignancy in coeliac disease - effect of a gluten-free diet. Malignancy in coeliac

7 Sheldon W. Prognosis in early adult life of coeliac children treated with a gluten-free diet. $B M F$ 1969; ii: $401-4$.

8 Young WF, Pringle EM. 110 children with coeliac disease 1950-1969. Arch Dis Child 1971; 46: 421-36.

9 Mortimer PE, Stewart JS, Norman AP, Booth CC. Follow-up study of coeliac disease. BMF 1968; iii: 7-9.

10 Weir DG, Hourihane D O'B. Coeliac disease during the teenage period: the value of serial serum folate estimations. Gut 1974; 15: 450-7.

11 Kumar PJ, Harris G, Walker-Smith JA, Milla P, Clark ML. The teenage coeliac. Gut 1985; 26: A551.

12 Kumar PJ, Walker-Smith J, Milla P, Harris G, Colyer J, Halliday R. The teenage coeliac: follow-up study of 102 patients. Arch Dis Child 1988; 63: 916-20.

13 Jackson PT, Glasgow JFT, Thom R. Parents' understanding of coeliac disease and diet. Arch Dis Child 1985; 60: 672-4.

14 Schmitz J, Battandier F, Jos J, Rey J. Long-term follow-up of childhood coeliac disease: is there a natural recovery? Pediatr Res 1984; 18: 1052.
15 Montgomery AMP, Goka AKJ, Kumar PJ, Farthing MJG, Clark ML. Low gluten diet in the treatment of adult coeliac disease: effect on jejunal morphology and serum antigluten antibodies. Gut 1988; 29: 1564-8.

16 Cameron N. The methods of auxological anthropometry. In: Falkner F, Tanner JM, eds. Human growth. New York: Plenum Press, 1977.

17 Capozzi G, Vitiello N, Greco L, et al. Factors related to growth in height: are regional standards still required? Ital $\mathcal{F}$ Pediatr 1988; 14: 384.

18 Mayer M, Greco L, Troncone R, Grimaldi M, Panza GP. Early prediction of relapse during gluten challenge in childhood celiac disease. F Pediatr Gastroenterol Nutr 1989; 8: 474-9.

19 Niazi NM, Leigh R, Crowe P, Marsh MN. Morphometric analysis of small intestinal mucosa. I. Methodology, epithelial volume compartments and enumeration of interepithelial space lymphocytes. Virchows Arch [A] 1984; 404: 49-60.

20 Marsh MN, Hinde J. Morphometric analysis of small intestinal mucosa. III. The quantitation of crypt epithelial volumes and lymphoid cell infiltrates, with reference of coeliac sprue mucosa. Virchows Arch [B] 1986; 409: 11-2.

21 Marsh MN. Studies of intestinal lymphoid tissue. XI - The immunopathology of cell-mediated reactions in gluten sensitivity and other enteropathies. Scanning Microsc 1988; 3: 1663-84.

22 Baker PG, Barry RE, Read AE. Detection of continuing gluten ingestion in treated coeliac patients. $B M \mathcal{F} 1975 ; \mathrm{i}: 486-8$

23 Paerregaard A, Vilien M, Krasilnikoff PA, Gudman-Hyer E. Supposed coeliac disease during childhood and its presentation 14-38 years later. Scand $\mathcal{F}$ Gastroenterol 1988; 23: 65-70.

24 Kokkonen J, Viitanen A, Simila S. Coping with a coeliac diet after adolescence. Helv Paediat Acta 1988; 43: 261-5.

25 Guandalini S, Ventura A, Ansaldi N, Giunta AM, Greco L Lazzari R, et al. Diagnosis of coeliac disease: time for a change? Arch Dis Child 1989; 64: 1320-5.

26 Kuitunen $P$, Savilahti E, Verkasalo $M$. Late mucosal relapse in a boy with coeliac disease and cow's milk allergy. Acta Paediatr Scand 1986; 75: 340-2

27 Marsh MN. Measurement of intra-epithelial lymphocytes. Gut 1986; $27:$ 1516-7.

28 Ferguson A, Ziegler K. Intra-epithelial lymphocyte mitosis in a jejunal biopsy correlates with intra-epithelial lymphocyte count, irrespective of diagnosis. Gut 1986; 27: 675-9.

29 Stein H, Sperling M, Dienemann D, Zeitz M, Riecken EO. Identification of a $\mathrm{T}$ cell lymphoma category derived from intestinal mucosa associated T cells. Lancet 1988; ii: 1053-4. 